\title{
Rainfall Accuracy Considerations Using Radar and Rain Gauge Networks for Rainfall-Runoff Monitoring
}

\author{
Baxter E. Vieux and Jean E. Vieux
}

Components of urban drainage during wet weather affecting water quality in receiving waters are stormwater and overflows from sanitary or combined sewers. A common element affecting each of these components is the spatial distribution of rainfall over contributing areas. Knowing quantities of stormwater arriving at inlets, infiltrating into sanitary sewers, and the inflow into combined sewers is critical to successful hydraulic model calibration and sewer system design. Accuracy and representativeness of the spatial and temporal distribution of rainfall over contributing areas is an important determinant of model accuracy. It is not always feasible to install sufficient rain gauges to measure spatially representative rainfall over a metropolitan sewer district at the scale of sewersheds. Nor is it feasible to install streamflow monitoring stations or sample priority pollutants in every impacted watershed. Thus the combination of radar and rain gauges to characterize the distribution of rainfall offers technical advantages for monitoring both rainfall and runoff in urban areas. Evaluation of a 55-event series, the median accuracy, as measured by gauge-radar comparison, has a median average difference of $\pm 8 \%$. Gauge network density requirements should take into account the variability of precipitation, distribution over sewershed areas, and local or climatological trends caused by terrain or large water bodies. Runoff measured by streamflow is used to validate the radar to gauge correction and to test the influence of random and systematic error in the radar input. Because simulated runoff is dependent on the rainfall input

Vieux, B. and J. Vieux. 2005. "Rainfall Accuracy Considerations Using Radar and Rain Gauge Networks for Rainfall-Runoff Monitoring." Journal of Water Management Modeling R223-17. doi: 10.14796/JWMM.R223-17. (C) CHI 2005 www.chijournal.org ISSN: 2292-6062 (Formerly in Effective Modeling of Urban Water Systems. ISBN: 0-9736716-0-2) 
uncertainty, runoff simulated using gauge-corrected radar is evaluated for a series of five storms composed of both tropical storms and convective events. For the five storm events over Brays Bayou in Houston Texas, the predicted hydrograph volume depends on the uncertainty of the radar input. Using the gauge-corrected radar as input, the rainfall-runoff model is able to predict volume to within $\pm 7.8 \mathrm{~mm}$, which is nearly identical to the uncertainty of the input, $\pm 7.98 \mathrm{~mm}$ as measured by radar-gauge comparison. The influence of uncorrected radar (bias) is much greater than the random errors that remain in the gauge-corrected radar inputs as demonstrated by a distributed runoff model. Accurate rainfall derived from a combined system of radar and gauges reduces input- and model-output errors associated with rainfall that is not representative over the drainage areas modeled.

\subsection{Introduction}

Technological advances in weather surveillance radar and rain gauge network telemetry have improved our ability to measure rainfall over large areas in real-time and in reconstruction of flow-monitored events. Such measurements must be broad-scale over large watershed areas, yet with sufficient resolution to be useful for sewersheds as small as a few square kilometers. Characterization of rainfall for stormwater runoff, inflow and infiltration, calibration of sewer system models, system design, and predictive real-time control has important benefits. Better agreement between observed and simulated hydrographs is achieved with rainfall that is representative over the watershed. Further, high-resolution rainfall makes it possible to produce runoff and inflow estimates that affect sewer system operation efficiency and treatment capacity. The characteristics and statistical control of the measurement process provides valuable information to users engaged in rehabilitation, improvements, model calibration, and operation of sewer systems.

This chapter is organized in three parts. First, a description of rainfall measurement using gauge networks alone and in combination with radar measurements is given. Following this, the influence of rainfall measurement accuracy on runoff prediction is presented. Finally, a summary outlines the major considerations for design and operation of rainfall monitoring and runoff prediction systems. 


\subsection{Rainfall Monitoring}

Historically, rainfall data for hydrologic applications have been obtained from only a few gauges, or at best, a sparse network of rain gauges. Rain gauges sample rain at distinct points and therefore may not accurately reflect the spatial distribution of rainfall over a watershed or region. Interest in using radar estimates of rainfall comes from the desire to reduce errors due to imprecise knowledge of rainfall distribution in time and space. Rain gauges when maintained and distributed over a region or watershed are useful for enhancing the accuracy of radar measurements. When radar and gauges are combined, rainfall measurement can be both accurate and representative of the spatial distribution of rainfall. With combined radar-gauge systems, fewer gauges are needed than when gauges are used alone. The following describes the considerations that can be used to develop rain gauge networks for the specific purpose of statistically correcting radar rainfall.

\subsubsection{Rain Gauge Network Density}

While a single rain gauge can be used alone for hydrologic model input, a network of rain gauges is preferred. A network composed of many gauges is used to characterize precipitation over an area such as a watershed. Such a network can be used alone or in conjunction with radar to measure spatially variable rainfall. The network characteristics of density, recording method, telemetry, precision, and type of equipment affect the accuracy and representativeness of the data collected by the network. Storm type, convective or stratiform, and climatic factors also enter into planning a network. During rainfall dominated by convective storms intense precipitation often occurs over small areas with high variability. Stratiform rainfall is typically more widespread and less variable. Climatological gradients near large water bodies such as the Great Lakes or in coastal zones can result in a trend from higher precipitation accumulation near the shore towards lower amounts inland. Orographic enhancement of precipitation produces a similar trend where precipitation increases with elevation. Capturing the trend caused by large water bodies and mountainous terrain can be important both at the event scale and climatologically over longer time scales.

Characterizing the distribution of rainfall geographically over an urban area requires consideration of the observational system in relation to the variability of the rainfall at the event and climatological time scales. Capturing storms with small spatial extent requires a denser network than one 
designed to capture climatological long-term averages. A convective storm event may pass through a gauge network and only affect a small number of gauges because of the limited spatial extent of the storm. A network that is too sparse may result in incomplete measurement of a rainfall event because the gauges in the network do not record the most intense parts of the storm. Because the rainfall variability was not captured, the rainfall data is not representative over the area and erroneous modeling may result.

General recommendations on gauge network density have been made primarily for gauge-only estimation of rainfall. A study was conducted by the US Weather Bureau (now the National Weather Service) on the number of rain gauges needed to characterize rainfall over the Muskingum River Basin, Ohio. The US Army Corps of Engineers, citing this study, reports the gauge density required for hydrologic modeling in relation to watershed area (U.S. Army Corps of Engineers, 1996). The number of gauges, $N_{g}$, is,

$$
N_{g}=A^{0.33}
$$

where $A$ is the watershed area in $\mathrm{mi}^{2}\left(2.59 \mathrm{~km}^{2}=1 \mathrm{mi}^{2}\right)$.

The number of gauges for a range of watershed areas may be computed using Equation 17.1, as presented in Table 17.1. The number of gauges recommended by Equation 17.1 is quite small when compared to typical urban rain gauge networks where densities may be as great as one gauge per 10 to $20 \mathrm{~km}^{2}$.

Table 17.1 Gauge number and density based on drainage area (Equation 17.1)

\begin{tabular}{cllll}
\hline Number & $\begin{array}{l}\text { Area } \\
\left(\mathrm{mi}^{2}\right)\end{array}$ & $\begin{array}{l}\text { Area } \\
\left(\mathrm{km}^{2}\right)\end{array}$ & $\begin{array}{l}\text { Density } \\
\left(\mathrm{km}^{2} / \text { gauge }\right)\end{array}$ & $\begin{array}{l}\text { Density } \\
\left(\mathrm{mi}^{2} / \text { gauge }\right)\end{array}$ \\
\hline 1 & 0.386 & 1 & 1.0 & 0.4 \\
2 & 3.86 & 10 & 5.0 & 1.9 \\
3 & 38.6 & 100 & 33.3 & 12.9 \\
7 & 386 & 1000 & 142.9 & 55.2 \\
12 & 1931 & 5000 & 416.7 & 160.9 \\
\hline
\end{tabular}

For a catchment of $100 \mathrm{~km}^{2}$, Equation 17.1 would suggest only three gauges with a density of one gauge per $33.3 \mathrm{~km}^{2}$. Equation 17.1 is based solely on the 
size of the watershed, which only indirectly takes into account the spatial variability of the rainfall and the timescale of rainfall (hourly, daily, or monthly) to be captured by the gauge network.

From the Muskingum River basin analysis, the accuracy, expressed in terms of the standard error, is dependent on the number of gauges in the basin. Analysis of rain gauge data from these watersheds revealed that the standard error is reduced through the addition of more gauges. However, reducing the standard error of measurement from just $15 \%$ to $10 \%$ required four times the number of gauges.

A similar approach to identifying the number of gauges based on the standard error is set forth by ASTM D 4430-96. This standard presents a method for meteorological measurements to establish both the temporal and spatial distribution of atmospheric quantities by repeated measurements where dissimilar measurement systems are used to measure the same quantity, e.g., radar and rain gauges. According to this standard, the accuracy of a rain gauge network is deemed sufficient if it accurately measures or is representative of rainfall over an area. The number of measurements, $N_{n}$ is determined such that the difference $D$ between the sample mean $d$ and the true mean $\mu$ is less than or equal to three times the standard deviation $s$ about the mean. The confidence associated with the criterion of three standard deviations, $3 s$, is $99.7 \%$. For this criterion, the difference, $D$, between the mean of the sample set and the true mean is

$$
D \leq \frac{3 s}{\sqrt{N}}
$$

If a rainfall event has an estimated standard deviation, $s=20 \mathrm{~mm}$, and 20 gauges are used to measure the rainfall depth, then the difference between the sample and true mean with $99.7 \%$ confidence $(3 s)$ is:

$$
\begin{aligned}
& s=20 \mathrm{~mm} \\
& N=20 \\
& D=13 \mathrm{~mm} \text { with } 99.7 \% \text { Confidence }
\end{aligned}
$$

According to ASTM D 4430-96, the sampling is not complete until $D$ is less than or equal to one increment of the resolution $r$ of the system being tested. The resolution $r$ is the standard error that depends on the requirements of the application. Rearranging Equation 17.2, the number of samples $N$ needed is,

$$
N \geq\left(\frac{3 s}{r}\right)^{2} 99.7 \% \text { confidence }
$$


For example, if a rainfall event has an estimated standard deviation, $s=20$ $\mathrm{mm}$, and the precision of measurement is desired to be within $r=10 \mathrm{~mm}$, then the number of gauges $N$ needed, with $99.7 \%$ confidence $(3 s)$ is:

$$
\begin{aligned}
& s=20 \mathrm{~mm} \\
& r=10 \mathrm{~mm} \\
& N=36 \text { with } 99.7 \% \text { confidence }(3 s)
\end{aligned}
$$

For less restrictive confidence levels, the number $N$ is substantially reduced to achieve a required value of $r$. For two standard deviations $(2 s)$, the number of gauges $N$ will measure the rainfall depth to within the standard error $r$ with a confidence level of $95.5 \%$ :

$$
N \geq\left(\frac{2 s}{r}\right)^{2} 95.5 \% \text { confidence }
$$

The number of gauges is substantially reduced if the confidence level is relaxed from $3 s$ to $2 s$ with only a small decrease in confidence $(99.7 \%$ to 95.5\%).

$$
\begin{aligned}
& s=20 \mathrm{~mm} \\
& r=10 \mathrm{~mm} \\
& N=16 \text { with } 95.5 \% \text { confidence }(2 s)
\end{aligned}
$$

Equations 17.2 and 17.3 are based on using three standard deviations (3s) to compute the number of measurements, which imposes a high degree of confidence, $99.7 \%$, on the measurements. Increasing the confidence level from $95.5 \%(2 s)$ to $99.7 \%(3 s)$, which is a gain of just $4.2 \%$ in confidence, comes at a high price of adding 20 more gauges (16 to 36).

The confidence level of the sample mean falling within the resolution, $r$, should be considered in relation to the number of gauges required. Requiring a standard error based on just two standard deviations (2s), achieves a relatively high confidence level of $95.5 \%$. Figure 17.1 shows the number of gauges required for achieving a specified standard error, $r(\mathrm{~mm})$, with $95.55 \%$ confidence in the mean depth $(2 s)$. The families of curves are produced for standard deviations of $s=5$ to $50 \mathrm{~mm}$. The variability of the rainfall is accounted for by the standard deviation, $s$.

The standard error of the mean may serve as an estimate but does not consider the need for redundancy caused by gauge malfunction, spatial extent of the storm, accounting for climatological and orographic trends, or other factors that reduce reliability of a gauge network in operation. 


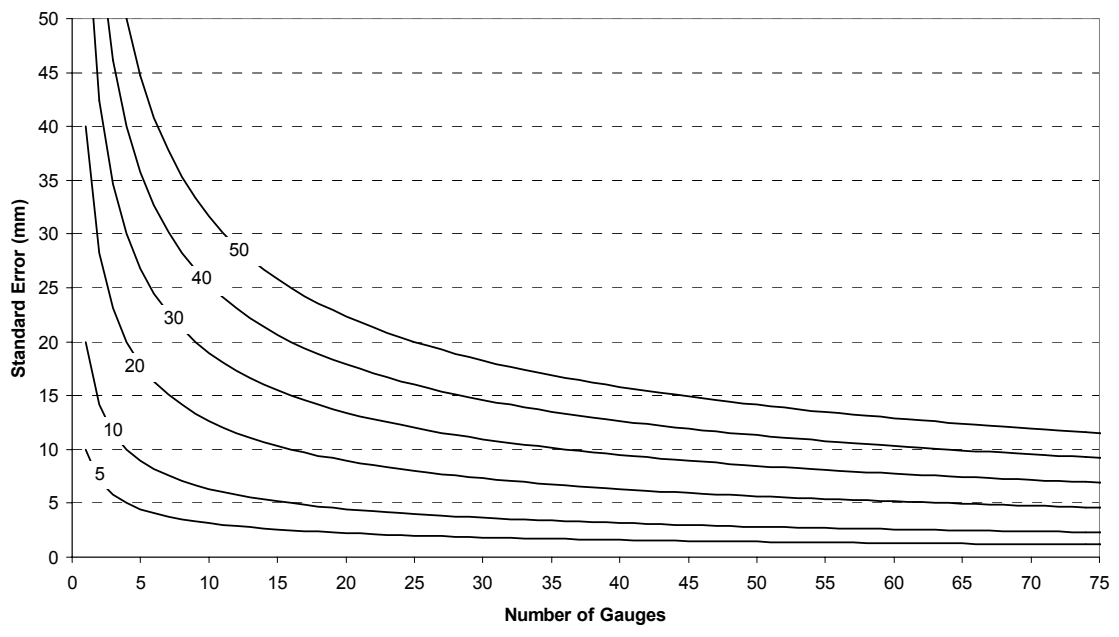

Figure 17.1 Number of gauges needed to achieve a specified standard error $(r)$ with $95.55 \%$ confidence level in the mean depth (2s). The families of curves are generated for rainfall standard deviation of $s=5,10$, 20, 30, 40, and $50 \mathrm{~mm}$ (Vieux, 2005).

For any particular event, the precipitation-producing storm may not cover more than a fraction of the gauges in the network. Because rainfall is spatially correlated, measurements obtained from a given set of gauges are not statistically independent. Therefore, more gauges (higher density) may be required than is estimated by the standard error associated with independent measurements.

Characterizing the variability of rainfall has important consequences on design of rainfall monitoring systems and urban infrastructure used to control urban drainage. A major effort to characterize urban runoff (and rainfall) was performed by EPA in 1986 in the Nationwide Urban Runoff Program (NURP). Best management practices for the reduction of pollutants in urban runoff were shown to be detention, recharge, and infiltration control techniques. Design of detention ponds and the expected long-term efficiency was shown to depend on the volume of the pond. The sizing of detention ponds and the expected removal efficiency of particulate pollutants depends on the variability of the rainfall. For a given size, a detention pond will overflow more often when rainfall is more variable. Rainfall statistics compiled as a part of the NURP study were and still are an important component in the analysis and design of detention ponds. EPA 440/5-87-001 
(USEPA, 1986) presents the methodology for detention pond design and NURP rainfall statistics. As an example, selected NURP rainfall statistics for Baltimore, MD are shown in Table 17.2. The volume or depth of rainfall $V$ is shown for the summer months June-September and on an annual basis. The average, intensity $I(\mathrm{in} / \mathrm{hr})$, duration of the event $D(\mathrm{hr})$, and mean inter-event time, MIT (hr), and the mean number of events per year and month are shown in the first two lines for the summer and annual periods. The variability of rainfall for a selected location from the NURP statistics is expressed in terms of the coefficient of variation, which is the standard deviation normalized by the mean. The statistics are separated according to summertime and annual to reflect the increase in variability associated with summer convective storm events.

The summer mean is $V=10.9 \mathrm{~mm}(0.43 \mathrm{in}$.) with a standard deviation, $s=$ $18 \mathrm{~mm}(0.714 \mathrm{in}$.) for a single rain gauge, respectively. For a variability of $s=$ $18 \mathrm{~mm}$ the number of gauges needed is characterized using Equation 17.4. For stated performance criteria of $r=10 \mathrm{~mm}$ and $95.5 \%$ confidence, the number of gauges $N$ is:

$$
N \geq\left(\frac{2 \cdot 18}{10}\right)^{2}=12.96 \text { at } 95.5 \% \text { confidence }
$$

For this degree of variability $(s=18 \mathrm{~mm}$ ), the number of gauges should be at least $N=13$ to achieve the specified confidence level and standard error. Note that this approach does not consider the area over which the gauge network is distributed.

In general, as the area increases, so does the variability of the rainfall and the number of gauges required to achieve a given degree of accuracy and confidence level. The number of gauges using the method outlined is based on gauge-only measurement of rainfall. The combination of radar and gauges is discussed in the following section.

\subsubsection{Combined Gauge and Radar Measurement}

Weather radar measures the spatial pattern of rainfall at higher resolution than even the most dense rain gauge network. The resolution of the WSR-88D (NEXRAD) radar deployed in the US is currently set at 1 degree in azimuth by $1 \mathrm{~km}$ in range. The NWS Radar Operations Center has plans to upgrade the radar product generator (RPG) software in the future, which will enhance the 
resolution. The range will be quartered and the beam width halved producing an $8 \mathrm{x}$ increase in resolution.

Table 17.2 Selected rainfall statistics.

\begin{tabular}{|c|c|c|c|c|c|c|}
\hline Period & V (in) & I (in/h) & $\mathrm{D}(\mathrm{h})$ & MIT (h) & $\# \mathrm{r} / \mathrm{y}$ & $\# /$ month \\
\hline Annual & 0.400 & 0.069 & 6.000 & 82 & 107 & 9 \\
\hline Summer & 0.430 & 0.107 & 4.200 & 79 & 111 & 9 \\
\hline \multicolumn{7}{|c|}{ Coefficient of Variation (in) } \\
\hline & $\mathrm{V}_{\mathrm{v}}$ & $\mathrm{V}_{\mathrm{i}}$ & & & & \\
\hline Annual & 1.48 & 1.21 & & & & \\
\hline Summer & 1.66 & 1.49 & & & & \\
\hline \multicolumn{7}{|c|}{ Standard Deviation (in) } \\
\hline & $\mathbf{S}_{\mathbf{v}}$ & $\mathbf{s}_{\mathbf{i}}$ & & & & \\
\hline Annual & 0.592 & 0.084 & & & & \\
\hline Summer & 0.714 & 0.159 & & & & \\
\hline \multicolumn{7}{|c|}{ Standard Deviation (mm) } \\
\hline & $\mathbf{s}_{\mathbf{v}}$ & $\mathbf{s}_{\mathbf{i}}$ & & & & \\
\hline Annual & 15 & 2 & & & & \\
\hline Summer & 18 & 4 & & & & \\
\hline
\end{tabular}

While radar measurement accuracy is enhanced using rain gauges for bias correction, fewer rain gauges are needed than when rain gauges are used alone. Operational and maintenance considerations may require more gauges. In mountainous areas, more gauges may be needed to correct radar where precipitation rates are topographically enhanced. Various techniques have been applied to account for the orographic enhancement of precipitation. Placing additional gauges at higher elevations may be necessary to account for increased precipitation accumulations and to correct the radar rainfall measurement in areas of enhancement.

The true mean of the rainfall depth is impossible to know because the number of measurements is finite. The true mean can be better characterized with the high resolution of radar measurements than from a sparse rain gauge network because the spatial pattern of rainfall can in principal be better represented. Using two independent measurement systems to measure rainfall at the same geographic location (sampling the radar over each gauge), a 
systematic error (bias) can be computed. When corrected for this bias, the radar rainfall accuracy is enhanced. Once the systematic error is removed, random error remains. An average difference of rainfall depths between the two systems may be computed. This difference is a measure of agreement (uncertainty) between the two sensor systems.

Reflectivity is the signal strength returned by the hydrometeor and is dependent on the raindrop size distribution. Transforming reflectivity $Z$ into rainfall rate $R$, is achieved by use of a $Z-R$ relationship. A typical convective $Z-R$ relationship used in the WSR-88D is system is $Z=300 \mathrm{R} 1.4$. Once reflectivity is converted to rain rate, it is well known that systematic error, called bias, requires correction of the radar using rain gauges. Wilson and Brandes (1979) describe the adjustment procedure where the mean value of the radar field sampled over each gauge location is adjusted to coincide with the mean of the rain gauge measurements. This adjustment is known as mean field bias (MFB) correction or calibration. Calibration of radar hardware is a different process that affects the power of the transmitted (and therefore) received signals. Another popular method is the probability matching method (PMM) developed by Calheiros and Zawadzki (1987); Atlas et al. (1990); and Rosenfeld et al. (1993) that matches the means of the radar and gauge probability density functions for a set of gauge/radar measurements within a spatio-temporal window.

After applying a $Z-R$ relationship appropriate to the storm type, the systematic error or bias is removed through rain gauge correction. Bias between radar and gauge accumulations is computed as a multiplicative factor, F, as:

$$
F=\frac{\frac{1}{n} \sum_{i=1}^{n} G_{i}}{\frac{1}{n} \sum_{i=1}^{n} R_{i}}
$$

where:

$$
\begin{aligned}
G_{i} \text { and } R_{i} & =\text { the } i \text { th gauge-radar pairs of accumulations, and } \\
n & =\text { the number of pairs. }
\end{aligned}
$$

When $F$ in Equation 17.6 is computed for accumulations, $G_{i}$ and $R_{i}$, the period may be hourly, storm total, or other integration period during the event. Operationally, online application of this correction factor requires rain gauge measurements to be transmitted in near real-time. Correcting the radar bias is accomplished by multiplying radar accumulations by the factor, $F$. However 
random error still remains. The average difference after bias removal is an indicator of the uncertainty of the radar rainfall estimate. The average difference is defined as:

$$
\bar{D}=\frac{100 \%}{n} \sum_{i=1}^{n}\left|\frac{G_{i}-R_{i}^{*}}{G_{i}}\right|
$$

where $\mathrm{R}_{\mathrm{i}}{ }^{*}$ is the bias-corrected radar accumulation at the $i$ th gauge location.

The average difference is only an indication of the random error measured by comparison to rain gauges. Updrafts and downdrafts affect the rainfall rate, which is not detected by radar or between gauge locations.

Rain gauge errors cause uncertainty, too. Errors in gauge accumulations are caused by wind effects, rain shadows (trees etc.) and effects caused by heavy rainfall. Tipping bucket gauges are known to under-report during heavy rainfall rates because the mechanism cannot keep up with the time rate of arrival, or due to undercatch caused by splash out of the tipping bucket. The difference in scale between radar (areal) and gauge (point) measurements is another reason that radar will seldom agree exactly with gauge accumulations, even when sampled at the same location. Because of scale differences between the gauge and radar sample volume random error (differences) are expected.

As with any measurement system, both random and systematic errors exist. Systematic error, known as bias, requires correction. Random error is not correctable and is a part of any measurement. Examples of random and systematic errors affecting radar measurements are listed in Table 17.3.

Table 17.3 Examples of systematic and random errors in radar measurement of precipitation.

\begin{tabular}{ll}
\hline \multicolumn{1}{c}{ Systematic Errors } & \multicolumn{1}{c}{ Random Errors } \\
\hline Radar hardware calibration & $\begin{array}{l}\text { Updrafts (and down-) that decrease } \\
\text { or increase rain rates locally }\end{array}$ \\
\hline $\begin{array}{l}\text { Drop size distribution is different } \\
\text { than assumed in the Z-R } \\
\text { relationship }\end{array}$ & $\begin{array}{l}\text { Incomplete beam filling or high } \\
\text { gradient rainfall rates not } \\
\text { completely resolved by the radar } \\
\text { resolution }\end{array}$ \\
\hline
\end{tabular}

Other factors that affect the usefulness of radar include bright-band contamination during winter months, and overshoot of the radar beam in relation to precipitation generation processes in the atmosphere. 
With a $10 \mathrm{~cm}$ wavelength under most conditions, the useful range is considered to be $180 \mathrm{~km}$ even though the WSR-88D produces precipitation estimates out to $230 \mathrm{~km}$. As distance increases, the beam measures higher above average ground level (AGL) because of the angle of the first tilt beam, which is 0.5 degree. At $180 \mathrm{~km}$, the beam is $3.5 \mathrm{~km}$ AGL and may overshoot low clouds. Additional details on radar characteristics related to precipitation measurements may be found in Fulton et al. (1998); Doviak and Zrnic (1992, p. 223-231); with emphasis on hydrologic prediction, see Vieux (2005), Vieux (2002, p. 648-681); Vieux and Bedient (1998); Vieux and Bedient (2004), and Einfalt et al. (2004); and for details related to radar rainfall processing protocols for sewer system applications, refer to Vallabhaneni et al. (2004), Burgess et al. (2003), and Vieux and Vieux (2003).

Examining the statistical relationship between gauge and radar for a large number of events provides insight into the accuracy achieved using a realtime system. The 3 Rivers Wet Weather Demonstration Program maintains a radar rainfall monitoring program to support wet weather overflow reduction activities in Allegheny County. Eighty-three communities are located within this county including Pittsburg, Pennsylvania. A rain gauge network of 21 gauges within a bounding box of $828 \mathrm{~km}^{2}$ is maintained. This network has been expanded, however, during the period of the statistical analysis it consisted of the initial 21 gauges. Figure 17.2 shows the entire county area with the bounding box that contains the 21 gauges used to adjust radar rainfall. This network has now been expanded to cover more area than the initial concentration of gauges as shown here.

During the processing of each event, not all gauges are used. For the 55 events analyzed, on average, the number of gauges used was 16 of 21 per event, or about $75 \%$ of the gauges. A gauge is excluded during event processing because the gauge did not receive rainfall or it was discarded as a statistical outlier due to malfunction during an event. Computing statistics on the agreement between the gauge and radar accumulations provides valuable information useful to hydrologic and hydraulic modeling.

Analysis of the lower quartile rainfall events indicates that the expected average difference between gauge and radar measurements is $25.61 \%$. Upper quartile rainfall events have an expected average difference of $17.25 \%$. Overall, the events analyzed agree to within $\pm 8 \%$ based on the median average difference between gauge and radar. The rainfall statistics for these events are presented in Table 17.4. Because the radar rainfall sampled over the rain gauge location is adjusted so that the mean depth agrees, the two columns are nearly identical. Note that the standard deviation $s$ for both radar 
and gauge are the same because the mean values are made to agree through the bias correction process.

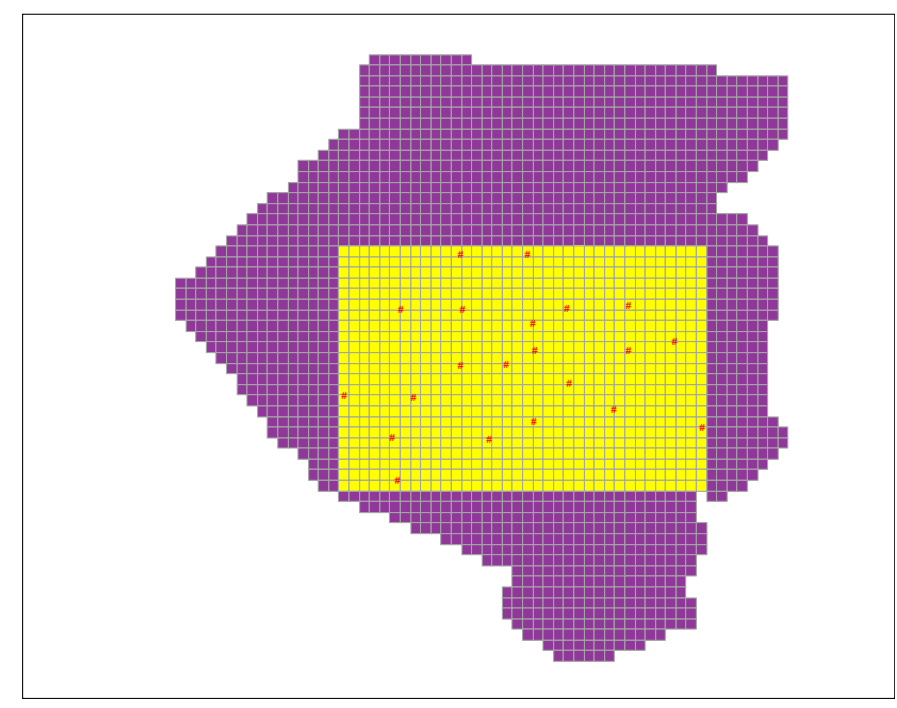

Figure 17.2 Rain gauge network and bounding box used to adjust radar rainfall measurements over Allegheny County, PA. The average distance between gauges is $6.28 \mathrm{~km}(3.9 \mathrm{mi})$ with one gauge per $39.4 \mathrm{~km}^{2}(15.2$ $\mathrm{mi}^{2}$ ) density.

In Figure 17.2 the following apply:

$$
\begin{array}{ll}
N=21 \text { gauges } & N=21 \text { gauges } \\
A=320 \mathrm{mi}^{2} & A=828 \mathrm{~km}^{2} \\
P=15.2 \mathrm{mi}^{2} \text { per gauge } & P=39.4 \mathrm{~km}^{2} \text { per gauge } \\
L=3.90 \mathrm{mi} & L=6.28 \mathrm{~km}
\end{array}
$$

Table 17.4 Mean depth and standard deviation of rainfall (55 events)

\begin{tabular}{lrr}
\hline Statistic & Gauge & \multicolumn{1}{c}{ Radar } \\
\hline $\mathrm{s}$ (in) & 0.40 & 0.40 \\
$\mathrm{~s}(\mathrm{~mm})$ & 10.16 & 10.16 \\
Mean Depth (in) & 0.53 & 0.53 \\
Mean Depth (mm) & 13.46 & 13.44 \\
\hline
\end{tabular}


The rainfall variability characterized by rain gauges alone or in combination with radar has important consequences on hydrologic modeling and characterizing the rainfall for wet weather discharge modeling, capacity assessment, and infiltration/inflow studies. Matching radar with gauge accumulations is not the sole aim of producing gauge-corrected radar. However, producing representative rainfall for hydrologic prediction and hydraulic sewer system modeling is the principal goal. The following section treats the subject of the effects of rainfall measurement uncertainty on hydrologic modeling.

\subsection{Distributed Runoff Prediction}

Knowing how much runoff is occurring at any location in a watershed requires the integration of distributed hydrologic prediction models, multisensor estimates of precipitation from radar, satellite and gauge, and information systems for hydrologic information dissemination. The overall goal of the fully-distributed, physics-based hydrologic model, $\mathrm{V} f l o^{\mathrm{TM}}$, is to provide high-resolution runoff estimation for management of water from small watersheds to river basin scale. An advantage of physics-based models is that they can be setup with minimal historical data and still generate meaningful results. Spatially explicit representation of the factors controlling runoff allows predictions that are more accurate. The influence of precipitation uncertainty on runoff prediction on runoff prediction may be identified by comparison of radar rainfall inputs and model outputs for a basin. A distributed model is required for such representation such as $\mathrm{V} f l o^{\mathrm{TM}}$.

$\mathrm{V} f l^{\mathrm{TM}}$ has the capability to simulate stormwater that runs off over the terrain represented by geographical maps such as digital elevation, soils, and land use/cover. Classically, hydrologic models have been optimized for point measurements, i.e., at a basin outlet, and not distributed in space and time. Distributed models avoid averaging parameters and input with the goal of more accurate representation of watershed characteristics. A computational scheme that routes runoff from grid cell to grid cell or other element representative of the landscape using a set of equations termed a mathematical analogy. Analogies range from full dynamic to simplifications such as diffusive and kinematic wave. The kinematic wave analogy is applicable in areas where the land surface slope is the dominant gradient and where backwater effects are not important. Physics-based models use conservation of mass, momentum, and energy equations to represent hydrologic processes, 
whereas conceptual models use empirical relationships to represent component processes.

The term physics-based model means that conservation of mass in combination with momentum and/or energy is employed to compute hydrologic fluxes. Using conservation laws, the hydraulics of the overland and channel drainage system determines the flow rates. This is in marked contrast to standard practice where the hydrology is considered separately from hydraulics. Deterministic physics-based models include $\mathrm{V} f \mathrm{fl}^{\mathrm{TM}}$ (Vieux and Vieux, 2002; Vieux, 2005); r.water.fea (Vieux and Gauer, 1994; Vieux, 2001), CASC2D (Julien and Saghafian, 1991; Ogden and Julien, 1994; Systeme Hydrologique European (SHE) (Abbott et al., 1986a,b) and the Distributed Hydrology Soil Vegetation Model (DHSVM) (Wigmosta, et al., 1994).

Rainfall derived from a combined system of radar and gauges that is representative over the drainage area allows the modeler to concentrate more on model parameterization and calibration, with less time spent on difficulties associated with non-representative rainfall. Depending on the model application, trying to match observed discharge in a sewer system or stream requires more effort than when simply applying a synthetic design storm. Flow-monitored events require representative rainfall over the watershed or sewered area contributing to the observed flow measurement. It is not uncommon to find that the observed flow-monitored response begins before the rain event when using rain gauges as the sole means for characterizing the rainfall over a watershed (Vallabhaneni et al., 2004). This counterintuitive result is caused by the rain gauge because the rainfall has already occurred over the contributing area before reaching the gauge. For this reason, obtaining rainfall that is representative is a major determinant in successful model calibration and application.

The importance of representative rainfall derived from radar is demonstrated in Brays Bayou, which is a well-characterized basin in Houston Texas (Vieux and Bedient, 2004). The agreement between radar and gauge accumulations for one of the most damaging tropical storms in US history, Tropical Storm Allison, is shown in Figure 17.3. Figure 17.4 is the distribution of rainfall over the basin area showing relatively light amounts over the western portion of the watershed and heavier amounts over the outlet (eastern portion).

The influence of the bias correction is seen in Figure 17.5 for a verification event, i.e. no model parameter adjustment. Widely varying hydrograph results from applying a range of bias correction factors. The expected bias correction based on agreement between simulated and observed 
stream flow would be 0.63 because of the coherence in hydrographs that is produced. The importance of gauge correction in both real-time and reconstruction is illustrated by the hydrograph peak/volume dependence on the radar input.

Statistical comparison of gauge and radar rainfall depths is presented in Table 17.5 for five events occurring over Houston Texas. The mean absolute percentage error (MAPE) for these events ranged from $11.7 \%$ to $21.2 \%$ after bias correction. On average for these events, MAPE $=16.8 \%$ with a mean depth of $95 \mathrm{~mm}$. Once the radar is bias-corrected by multiplication of the radar values by the mean field bias (MFB), the rainfall uncertainty is estimated according to the average MAPE between gauge and radar, which is $16.8 \%$. Considering the average depth of $95 \mathrm{~mm}$, this difference amounts to an accuracy of $\pm 7.98 \mathrm{~mm}$.

Table 17.5 Radar to gauge comparison. Depth in $(\mathrm{mm})$ is computed from adjusted radar above Main Street (Vieux and Bedient, 2004).

\begin{tabular}{lcccccc}
\hline \multicolumn{1}{c}{ Event } & MFB & MAPE Unadj & MAPE Adj & Rel Disp. & \#Gauges & Depth $(\mathrm{mm})$ \\
\hline Francis & 1.477 & 32.1 & 16.1 & 19.6 & 46 & 163.4 \\
${\text { Allison } 1^{\text {st }}}^{0}$ & 0.971 & 15.9 & 15.9 & 20.3 & 11 & 39.6 \\
Allison 2 $^{\text {nd }}$ & 0.623 & 68.3 & 21.2 & 41 & 10 & 74.3 \\
Allison $^{\text {rd }}$ & 0.636 & 61 & 19 & 24 & 10 & 96.7 \\
$8 / 15 / 2002$ & 0.836 & 23.8 & 11.7 & 18.8 & 15 & 101.1 \\
\hline Mean & 0.909 & $40.2 \%$ & $16.8 \%$ & 24.7 & 18.4 & 95 \\
\hline
\end{tabular}

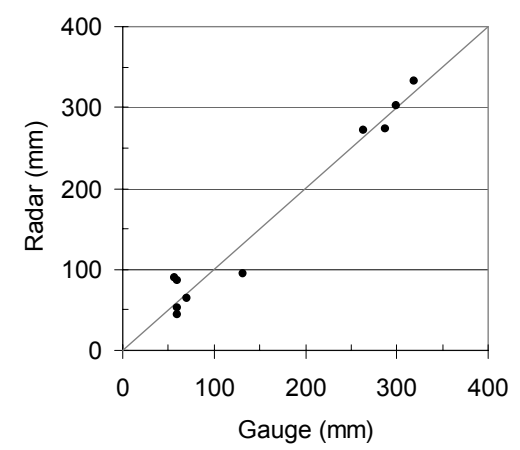

Figure 17.3 Gauge-adjusted radar and gauge accumulations during Tropical Storm Allison, June 8-9, 2001 (Vieux and Bedient, 2004). 


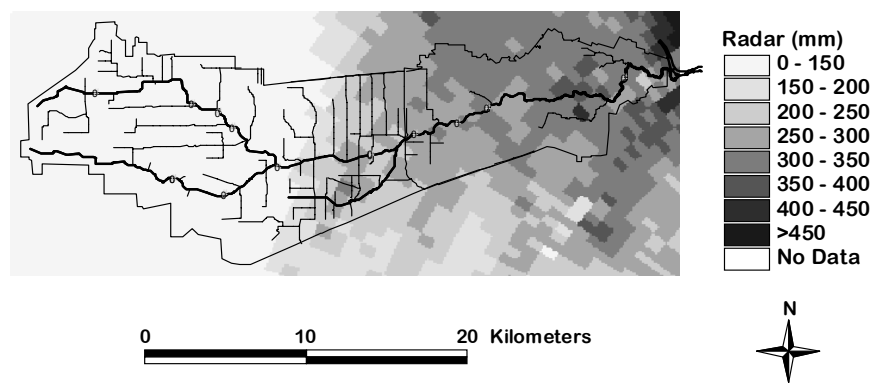

Figure 17.4 Allison rainfall distribution (Vieux and Bedient, 2004).

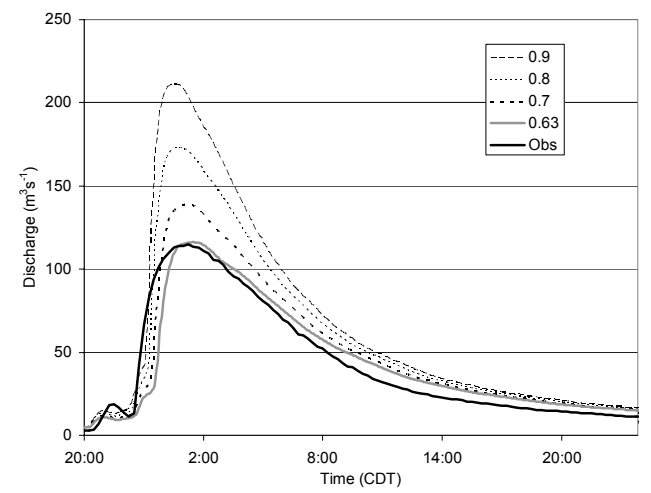

Figure 17.5 Hydrograph sensitivity to radar bias at Main Street (Vieux and Bedient, 2004).

In general, and as illustrated for Brays Bayou, the accuracy of modeled runoff is critically dependent on rainfall input. Taking streamflow measured by a USGS gauge at Main Street, a third independent observation system can be used to measure the accuracy of the input. Over the five events, the predicted hydrograph volume uncertainty at Main is MAPE $=21.2 \%$, which is less than the uncertainty indicated by radar to gauge comparison even after adjustment for bias. For the five events, using the bias-corrected radar as input, the model is able to predict volume to within $\pm 7.8 \mathrm{~mm}$, which is nearly identical to the uncertainty of the input, $\pm 7.98 \mathrm{~mm}$. When uncertainty is expressed as a percentage, the error in the input is larger than the uncertainty in the basin output suggesting that random error averages out over the watershed area. 


\subsection{Summary}

Combining weather surveillance radar and rain gauge network measurements improves the measurement accuracy of rainfall in real-time and in reconstruction of flow-monitored events. Characterization of rainfall for stormwater runoff, inflow and infiltration, calibration of sewer system models, system design, and predictive real-time control benefits from knowing how much rain fell over contributing areas during specific periods. Rain gauge network design should take into account the desired performance criteria in terms of accuracy and confidence in the mean rainfall depth measured. The number of gauges required to achieve a given level of accuracy increases dramatically when confidence levels are increased from 95.5 to $99.7 \%$. Fewer gauges are needed when combined with radar than when used alone. Approximately $25 \%$ more gauges were needed to allow for gauge malfunction or statistical outlier exclusion. When the uncertainty in rainfall produced from a combined system of radar and gauges is observed over a 55 -event series, the uncertainty is $\pm 8 \%$ for a specific gauge network with a density of one gauge per $39.2 \mathrm{~km}^{2}$.

Characterizing the spatial patterns of rainfall input can be a fundamental limitation in model calibration, validation, and application when using actual rainfall as input for comparison to flow-monitored discharge. When gaugeradar uncertainty (model input) is compared with predicted-observed streamflow (model output), the random errors tend to compensate over a watershed area. If not corrected, systematic error (radar bias) can have a large influence on rainfall-runoff modeling. Real-time operation of a distributed model benefits from real-time correction of radar from telemetered gauge networks. The uncertainty expressed by the gauge-radar average difference is not as great as the uncertainty in streamflow predictions due to averaging of random errors in the input over the watershed area. The influence of uncorrected radar (bias) is much greater than the random errors that remain in the gauge-corrected radar inputs as demonstrated by a distributed runoff model. Radar in combination with rain gauges can produce accurate and representative rainfall over drainage areas for hydrologic and hydraulic modeling applications. Without gauge correction, radar rainfall will likely contain systematic error and produce unrealistic or erroneous rainfall estimates. 


\section{Acknowledgments}

The research results presented were made possible by the OARS award for project number AR03(2)-067 from the Oklahoma Center for the Advancement of Science and Technology. The authors wish to thank John Schombert, Executive Director, 3 Rivers Wet Weather Demonstration Program for providing the rain gauge data for this analysis.

\section{References}

Abbott, M.B., J.C. Bathurst, J.A. Cunge, P.E O'Connell, and J. Rasmussen, 1986a. An introduction to European Hydrological System -Systeme Hydrologique Europeen, "SHE", 1 History and philosophy of a physically-based distributed modeling system., J. Hydrol., 87, 45-59.

Abbott, M.B., J.C. Bathurst, J.A. Cunge, P.E O'Connell, and J. Rasmussen, 1986b. An introduction to European Hydrological System-Système Hydrologique Européen, "SHE", 2 Structure of a physically-based distributed modeling system, J. Hydrol., 87, 61-77.

Atlas, D., D. Rosenfeld, and D. B. Wolff, 1990. Climatologically tuned reflectivity-rain rate relations and links to area-time integrals, J. Appl. Meteorol., 29, 1120-1135.

Burgess, E.H., B.E. Vieux, S. Moisio, and R.C. Johnstone. Design storm analysis of sewer system capacity. Proceedings of the 76th Annual Conference of the Water Environment Federation, October 11-15, 2003, Los Angeles, CA.

Calheiros, R. V., and I. Zawadzki, 1987. Reflectivity-rain rate relationships for radar hydrology in Brazil. J. Clim. Appl. Meteorol., 26, 118-132.

Doviak, R.J. and D.S. Zrnic., 1992. Doppler Radar and Weather Observations, Second edition, Academic Press, San Diego, CA.

Einfalt, T., K. Arnbjerg-Nielsen, D. Faure, N.-E. Jensen, M. Quirmbach, G. Vaes, B.E. Vieux, C. Golz. Towards a Roadmap for Use of Radar Rainfall Data in Urban Drainage. J. of Hydrology. Special Issue on Urban Hydrology, 299, 186-202.

Fulton, R. A., J. P. Breidenbach, D. J. Seo, D. A. Miller, and T. O'Bannon, 1998. The WSR-88D rainfall algorithm, Wea. Forecasting, 13, 377-395.

Julien, P.Y. and B. Saghafian, 1991. CASC2D user manual - a two dimensional watershed rainfall-runoff model. Civil Engineering Rep. CER90-91PYJ-BS-12, Colorado State University, Fort Collins.

Ogden, F.L, and P.Y. Julien, 1994. Runoff model sensitivity to radar rainfall resolution, J. Hydrol., 158, 1-18.

Rosenfeld, D., D. B.Wolff, and D. Atlas, 1993. General probability-matched relations between radar reflectivity and rain rate, J. Appl. Meteor., 32, 50-72.

U.S. Army Corps of Engineers, 1996. Hydrologic Aspects of Flood Warning Preparedness Programs. Technical Letter 1110-2-540, Washington, DC. 
U.S. EPA, 1986. EPA 440/5-87-001. Methodology for Analysis of Detention Basins for Control of Urban Runoff Quality. Office of Water, Nonpoint Source Pollution Branch,

Vallabhaneni, S., B. V. Vieux and T. Meeneghan. 2004. "Radar-Rainfall

Thechnology Integration into Hydrologic and Hydraulic Modeling Projects." Journal of Water Management Modeling R220-02. doi: 10.14796/JWMM.R220-02.

Vieux, B.E. and N. Gauer, 1994. Finite Element Modeling of Storm Water Runoff Using GRASS GIS, Microcomputers in Civil Engineering, 9(4), 263-270.

Vieux, B.E., and P.B. Bedient, 1998. Estimation of Rainfall for Flood Prediction from WSR-88D Reflectivity: A Case Study, 17-18 October 1994. Amer. Meteorol. Soc., J. of Weather and Forecasting, 13, 126-134.

Vieux, B.E., 2002. Radar Rainfall Applications in Hydrology. Chapter 11 in Bedient, P.B. and W.C. Huber, Hydrology and Floodplain Analysis, Addison-Wesley Publishing Co., Reading, Massachusetts, Third Edition.

Vieux, B.E. and J.E. Vieux, 2003, Development of a Radar Rainfall System for Sewer System Management. Proceedings of Sixth International Workshop on Precipitation in Urban Areas Measured and Simulated Precipitation Data Requirements for Hydrological Modelling, 4-7 December, Pontresina, Switzerland.

Vieux. B.E., 2005. Distributed Hydrologic Modeling Using GIS, Second Edition. Vol. 48 Water Science Technology Series. ISBN 1-4020-2459-2, Kluwer Academic Publishers, Norwell, Massachusetts.

Vieux, B.E., P.B. Bedient, 2004. Assessing urban hydrologic prediction accuracy through event reconstruction. J. of Hydrol.. Special Issue on Urban Hydrology, 299(1-4), $217-$ 236.

Wigmosta, M.S., L.W. Vail, and D.P. Lettenmaier, 1994. A distributed hydrologyvegetation model for complex terrain, Water Resources Research, 30(6), 1665-1669.

Wilson, J. and Brandes, E., 1979. "Radar measurement of rainfall—A summary." Bull. Amer. Meteor. Soc., 60, pp. 1048-1058.

Zawadzki, I. I., 1973. Statistical properties of precipitation patterns, J. Appl. Meteor., 12, 459-472.

Zawadzki, I. I., 1975. On radar-raingage comparison, J. Appl. Meteorol., 14, 1430-1436. 